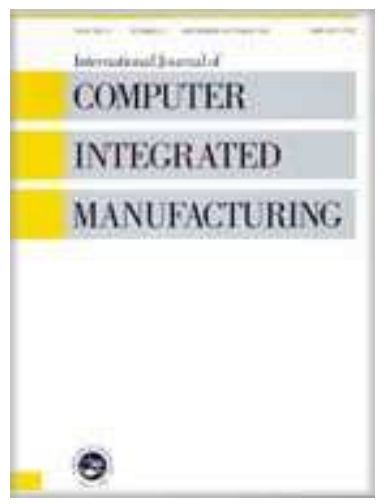

\title{
Geometrical position tolerance assignment in reverse engineering
}

\begin{tabular}{|r|l|}
\hline Journal: & International Journal of Computer Integrated Manufacturing \\
\hline Manuscript ID: & TCIM-2006-IJCIM-0082.R1 \\
\hline Manuscript Type: & Original Manuscript \\
\hline Author: & O4-Oct-2006 \\
\hline & $\begin{array}{l}\text { Complete List of Authors: } \\
\text { Kaisarlis, George; National Technical University of Athens (NTUA), } \\
\text { School of Mechanical Engineering, Dept. of Mechanical Design \& } \\
\text { School of Mechanos; National Engineering, Dept. of Mechanical Design \& } \\
\text { Sfantsikopoulos, Michael; National Technical University of Athens } \\
\text { (NTUA), School of Mechanical Engineering, Dept. of Mechanical } \\
\text { Design \& Control Systems }\end{array}$ \\
\hline Keywords: & $\begin{array}{l}\text { METROLOGY, REVERSE ENGINEERING, CMM, MANUFACTURING } \\
\text { ENGINEERING, TOLERANCING }\end{array}$ \\
\hline Keywords (user): & REVERSE ENGINEERING, TOLERANCING \\
\hline
\end{tabular}

\section{S ScholarONE" \\ Manuscript Central}




\title{
Geometrical position tolerance assignment in reverse engineering
}

\author{
G. J. KAISARLIS*, S. C. DIPLARIS $\dagger$ and M. M. SFANTSIKOPOULOS $\ddagger$
}

School of Mechanical Engineering, Dept. of Mechanical Design \& Control Systems, National Technical University of Athens (NTUA), "M" Building, Heroon Politechniou 9, 157 73, Zografou (Athens), Greece.

*Corresponding author.

E-mail: gkaiss@central.ntua.gr, Tel.: (+30) 210 7723682, Fax: (+30) 2107723599

†E-mail: stdiplar@central.ntua.gr, Tel.: (+30) 210 7721665, Fax: (+30) 2107723599

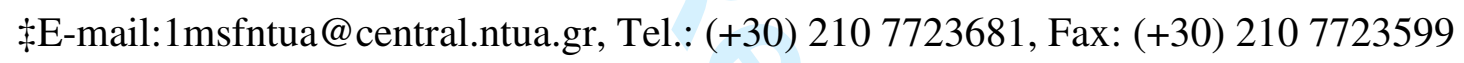




\title{
Geometrical position tolerance assignment in reverse engineering
}

\author{
G. J. KAISARLIS*, S. C. DIPLARIS and M. M. SFANTSIKOPOULOS
}

School of Mechanical Engineering, Dept. of Mechanical Design \& Control Systems, National Technical University of Athens (NTUA), “M” Building, Heroon Politechniou 9, 157 73, Zografou (Athens), Greece.

${ }^{*}$ Corresponding author.

Geometric dimensioning and tolerancing constitutes the dominant approach for design and manufacture of mechanical parts that controls inevitable dimensional and geometric deviations within appropriate limits. Position tolerance is a critical geometric tolerance very frequently used in industry. Its designation requires size data in conjunction with appropriate datums and location coordinates for the position. In reverse engineering, where typically relevant engineering information does not exist, conventional, human-based, trial and error approach for the allocation of positional tolerances requires much effort and time and offers no guarantee for the generation of the best of results. This is mainly due to the large number of possible data combinations and the applicable relationships that have to be developed and processed. A methodology that aims to the systematic solution of this problem in reasonable computing time and provides realistic and industry approved results is presented, demonstrated and discussed in the paper. 
Keywords: Reverse Engineering; Tolerancing; Geometric Tolerances; Position Tolerance

\section{Nomenclature:}

\begin{tabular}{cl}
\hline DF & Datum Feature \\
F & RE Feature
\end{tabular}

LMCD Least Material Condition, Diameter

MD Measured Diameter

MFE Measured Form Deviation

MMCD Maximum Material Condition, Diameter

MOE Measured Orientation Deviation

n Number of candidate DRFs

p, q Number of theoretical (Basic) X, Y dimensions (coordinates)

$\mathrm{R}_{\mathrm{CAN}} \quad$ Candidate Set

$\mathrm{R}_{\mathrm{SAG}} \quad$ Suggested Set

$\mathrm{T}_{\mathrm{POS}} \quad$ Position Tolerance

$\mathrm{u} \quad$ Number of reference RE components

X, Y Theoretical (Basic) dimensions (coordinates)

$\mathrm{X}^{\mathrm{M}}, \mathrm{Y}^{\mathrm{M}} \quad$ Measured dimensions (coordinates) 


\section{Introduction}

In manufacturing, deviations from the nominal geometric and dimensional requirements of a mechanical part are expected due to the stochastic nature of the actually achieved accuracy. Geometric Dimensioning and Tolerancing (GD\&T) constitutes the dominant approach for the design and manufacture of mechanical parts that controls these inevitable deviations within appropriate limits. In engineering drawings GD\&T correlates size, form, orientation and location of the geometric elements of the design model with the design intent, therefore it has a profound impact on the manufacturability, ease of assembly, performance and ultimate cost of the component. High geometrical and dimensional accuracy leads to high quality; however, tight tolerances lead to an exponential increase of the manufacturing cost.

Tolerance assignment is an engineering task strongly based on experimental data, past experience, industrial databases and guidelines. In Reverse Engineering (RE) tolerancing is much more difficult to be successfully handled. In this case all or almost all of the original component design and manufacturing information is not available and the geometric accuracy specifications for component reconstruction have to be reestablished, one way or the other, practically from scratch. RE-tolerancing includes tolerance allocation in terms of the actual functionality of a prototype assembly, mapping of component experimental design modifications, spare part tolerancing for machines that are out of production or need improvements and no drawings are available, damage repair, engineering maintenance etc. The task requires increased effort, cost and time, whereas the results, usually obtained by trial-and-error, may well be not the best. 
Although RE-tolerancing is a very important and frequently met industrial problem, the need for the development of a systematic approach to extract appropriate design specifications that concern the geometric accuracy of a reconstructed component has been only recently pointed out, (Motavalli and Shamsaasef 1996, Thompson et al. 1999, Borja et al. 2001, Várady and Martin 2002, VPERI 2003). Certain of its issues are also addressed by a limited number of research papers, (Werghi et al. 1999, Kaisarlis et al. 2000, Werghi et al. 2002, Kaisarlis et al. 2004). This paper further extends the research on this area by focusing on the RE assignment of Position Tolerances, as this type of geometrical tolerance is a widely used one in industry and almost always present in reverse engineering applications. The developed methodology addresses the problem in a systematic, time and cost efficient way, compatible with the current industrial insight. The approach, to the extent of the authors' knowledge, is the first of the kind for this type of RE problems that can be directly implemented within a CAD environment. It can also be considered as a pilot for further research and development in the area of RE tolerancing. The method use and effectiveness are demonstrated through an actual industrial case study.

\section{Background and problem description}

Designation of a positional tolerance, as a tolerance design problem, has been studied under various aspects including tolerance analysis and synthesis, composite positional tolerancing, geometric tolerance propagation, datum establishment, inspection procedures, e.g., (Lehtihet and Gunasena 1991, Ngoi et al. 2000, Jiang and Cheraghi 2001, Park and Lee 2001, Pandya et al. 2002, Cheraghi et al. 2003, Xi et al. 2004, Anselmetti and Louati 2005). Position is a term used to describe the perfect location of a point, line or plane of a 
feature in relationship with a datum reference or other feature. Position Tolerance is the total permissible variation in the location of a feature about its exact true position (ASME Y14.5M 1994, ISO5458 1998). For cylindrical features such as holes or bosses the position tolerance zone is usually the diameter of the cylinder within which the axis of the feature must lie, the center of the tolerance zone being at the exact true position, figure 1(a), whereas for size features such as slots or tabs, it is the total width of the tolerance zone within which the center plane of the feature must lie, the center plane of the zone being at the exact true position. The position tolerance of a feature is denoted with the size of the diameter of the cylindrical tolerance zone (or the distance between the parallel planes of the tolerance zone) in conjunction with the theoretically exact dimensions that determine the true position and their relevant datums, figure 1(b). Datums are, consequently, fundamental building blocks of a positional tolerance frame in positional tolerancing. Datum features are chosen to position the toleranced feature in relation to a Cartesian system of three mutually perpendicular planes, jointly called Datum Reference Frame (DRF), and restrict its motion in relation to it. Positional tolerances often require a three plane datum system, named as primary, secondary and tertiary datum planes. The required number of datums $(1,2,3)$ is derived by considering the degrees of freedom of the toleranced feature that need to be restricted. Change of the datums and/or their order of precedence in the DRF results to different geometrical accuracies, figure 2.

\section{[Insert Figure 1 about here] \\ [Insert Figure 2 about here]}

Fundamental difference between GD\&T and conventional coordinate tolerancing is that the former creates explicitly defined coordinate systems and respective DRF. All features on a part are unambiguously related to these coordinate systems through geometric 
tolerances in feature control frames and geometrical deviations of location, orientation and run-out are thus controllable.

Position tolerances mainly concern clearance fits. They achieve the intended function of a clearance fit by means of the relative positioning and orientation of the axis of the true geometric counterpart of the mating features with reference to one, two or three Cartesian datums. The relationship between mating features in such a clearance fit may be classified either as a fixed or a floating fastener type (ASME Y14.5M 1994, Cho and Tu 2002, Drake 1999). Floating fastener situation exists where two or more parts are assembled with fasteners such as bolts and nuts, and all parts have clearance holes for the bolts. In a fixed fastener situation a bolt passes through a clearance hole in one part and threads into a tapered hole in the mating part.

GD\&T in RE must ensure that a reconstructed component will fit and perform well without affecting the function of the specific assembly. To observe interchangeability accuracy specifications of an RE component must comply with those of the mating part(-s). Basic issues of the assignment of a Position Tolerance in RE are included in table 1. The analytic approach below deals with these issues in order to produce a reliable and cost competent solution within realistic time.

[Insert Table 1 about here] 


\section{Theoretical Analysis}

Tolerance allocation in RE constitutes a non deterministic problem as its solution has to be pursued through the combination of both analytical (algorithmic) and knowledge-based tools. In that context, the developed methodology produces an RE-position tolerance in four sequential steps, figure 3. Floating fasteners are considered and at least two reference RE-parts that bear negligible or no wear need to be available.

In step (a) mathematical relationships that represent the geometric constraints are formulated. They are used for the establishment of an initial set of candidate position tolerances. A position tolerance specification comprises of the position tolerance size, the DRF and the theoretical dimensions (coordinates) of the position. Step (b) qualifies sets of suggested position tolerances out of the group (a). They have to conform with the measured data of the particular RE-feature. Step (c) produces a set of preferred position tolerances by filtering out the output of Step (b) using knowledge-based rules and/or guidelines. The capabilities and expertise of the particular machine shop, where the new components will be produced, and the cost-tolerance relationship are taken into consideration in Step (d) of the analysis, where the required position tolerance is finally obtained.

\section{[Insert Figure 3 about here]}

For every datum feature that can be considered for the assignment of the position tolerance of an RE-feature (e.g. hole), the input for the analysis consists of (i) measured form deviation of the datum feature (e.g. flatness) and (ii) the orientation deviation (e.g. perpendicularity) of the RE-feature axis of symmetry with respect to that datum. The 
orientation deviations of the latter with respect to the two other datums of the same DRF have also to be included (perpendicularity, parallelism, angularity). Input data relevant with the RE-feature itself include its measured size (e.g. diameter) and coordinates [e.g. X, Y measured dimensions by Coordinate Measuring Machines (CMM)] that locate its axis of symmetry. The dimensional tolerance limits of the RE-feature and, as well as, the minimum functional clearance between the RE-mating features (i.e. minimum functional clearance between hole and screw shaft in case of floating fasteners) are taken as given. Uncertainty of the measured data (e.g. ISO 10360-2 accuracy thresholds for CMMs) should conform with the pursued accuracy level.

\subsection{Position tolerance size}

Starting point for the establishment of both the DRFs and the theoretical dimensions of the RE-feature location, is the size of the position tolerance zone as it is determined by the minimum functional clearance between the RE-mating features. It ensures that mating features will assemble even at the worst case scenario, when they both are at Maximum Material Condition and located at the extreme of the tolerance zone, (ASME Y14.5M 1994),

$\mathrm{T}_{\mathrm{POS}}=$ minimum functional clearance between the RE-mating features

The maximum possible size of the above position tolerance is obtained by adding to it the dimensional tolerance zone of the RE-feature itself (i.e. hole for floating fasteners),

$$
\max \mathrm{T}_{\mathrm{POS}}=\mathrm{T}_{\mathrm{POS}}+\mathrm{LMCD}-\mathrm{MMCD}
$$




\subsection{Candidate DRFs}

To ensure proper RE-part mating and safeguard repeatability, datum features of the original part and those of the RE-part should, ideally, coincide. In order to observe this principle the original datum features and their order of precedence have to be confirmed. Initial recognition of datum features is performed in an interactive way by taking into consideration the function of the RE component and its locating or working surfaces. The accuracy constraints that have to do both with the spatial arrangement and the geometrical irregularities of these features have then to be satisfied. Geometrical deviations of form, e.g flatness of a datum feature, and the orientation error, e.g. perpendicularity of the RE-feature axis of symmetry with respect to that datum, should be equal or less than the position tolerance of equation (1),

$$
\max \left(\mathrm{MFE}_{\mathrm{DF}}\right) \leq \mathrm{T}_{\mathrm{POS}}, \quad \max \left(\mathrm{MOE}_{\mathrm{F}}\right) \leq \mathrm{T}_{\mathrm{POS}}
$$

The relationships (3) qualify all possible datums of the part. Out of these datums an initial set of DRFs is generated by taking all combinations in couples and in triads between them.

In the framework of this analysis only DRFs that arrest all degrees of freedom of the particular RE-feature and consequently have three or at least two datum features are taken into account. DRF qualification for geometric feasibility is verified by reference to the list of the valid geometrical relationships between datums quoted in ASME Y14.5.1M 1994. The geometric relationship for instance, for the usual case of three datum planes that 
construct a candidate DRF is in this way validated, i.e. the primary datum not to be parallel to the secondary and the plane used as tertiary datum not to be parallel to the line constructed by the intersection of the primary and secondary datum planes. Planar or axial datum features are considered by the method as primary when the axis of the RE-feature is perpendicular in the first case or parallel, in the second one, to them.

Mutual orientation errors of datum features in a valid DRF should be, in addition, equal or less than the position tolerance of equation (1),

$\max \left(\mathrm{MOE}_{\mathrm{DF}}\right) \leq \mathrm{T}_{\mathrm{POS}}$

All DRFs that validate the above requirements create the Candidate DRFs set, $R_{C A N} D R F$.

\subsection{Candidate theoretical dimensions}

Theoretical dimensions locate the axis of symmetry of the RE feature with reference to every one candidate member, $\mathrm{DRF}_{\mathrm{i}}$ of the $\mathrm{R}_{\mathrm{CAN} \_} \mathrm{DRF}$ set, $\mathrm{i}=1,2, \ldots, \mathrm{n}$. Let $\mathrm{R}_{-} \mathrm{X}_{\mathrm{ij}}^{\mathrm{M}}, \mathrm{R}_{-} \mathrm{Y}_{\mathrm{ij}}^{\mathrm{M}}$ be the respective sets of the measured location coordinates, $\mathrm{X}_{\mathrm{ij}}^{\mathrm{M}}, \mathrm{Y}_{\mathrm{ij}}^{\mathrm{M}}, \mathrm{j}=1,2, \ldots, \mathrm{u}$, where $\mathrm{u}$ is the number of the available reference RE-parts. The first members of Candidate theoretical dimensions sets, $R_{C A N_{-}} X_{i}, R_{C A N_{-}} Y_{i}$, are then obtained as the integral part of the minimum measured coordinates minus the position tolerance of equation (1),

$\mathrm{X}_{\mathrm{i} 1}=\operatorname{int}\left[\operatorname{minR} \_\mathrm{X}_{\mathrm{ij}}^{\mathrm{M}}-\mathrm{T}_{\mathrm{POS}}\right], \quad \mathrm{Y}_{\mathrm{i} 1}=\operatorname{int}\left[\operatorname{minR} \_\mathrm{Y}_{\mathrm{ij}}^{\mathrm{M}}-\mathrm{T}_{\mathrm{POS}}\right]$

Following members of the sets are calculated by an incremental increase, $\delta$, of $\mathrm{X}_{\mathrm{i} 1}, \mathrm{Y}_{\mathrm{i} 1}$, 


$\begin{array}{lc}\mathrm{X}_{\mathrm{i} 2}=\mathrm{X}_{\mathrm{i} 1}+\delta, & \mathrm{Y}_{\mathrm{i} 2}=\mathrm{Y}_{\mathrm{i} 1}+\delta \\ \mathrm{X}_{\mathrm{i} 3}=\mathrm{X}_{\mathrm{i} 2}+\delta, & \mathrm{Y}_{\mathrm{i} 3}=\mathrm{Y}_{\mathrm{i} 2}+\delta \\ \ldots \ldots \ldots \ldots \ldots \ldots \ldots \ldots \ldots \ldots \ldots \ldots \ldots \ldots & \\ \mathrm{X}_{\mathrm{ip}}=\mathrm{X}_{\mathrm{i}(\mathrm{p}-1)}+\delta, & \mathrm{Y}_{\mathrm{iq}}=\mathrm{Y}_{\mathrm{i}(\mathrm{q}-1)}+\delta\end{array}$

bounded by,

$\mathrm{X}_{\mathrm{ip}} \leq\left(\operatorname{maxR} \_\mathrm{X}_{\mathrm{ij}}^{\mathrm{M}}+\mathrm{T}_{\mathrm{POS}}\right), \quad \mathrm{Y}_{\mathrm{iq}} \leq\left(\operatorname{maxR} \_\mathrm{Y}_{\mathrm{ij}}^{\mathrm{M}}+\mathrm{T}_{\mathrm{POS}}\right)$

with the populations $\mathrm{p}, \mathrm{q}$ not necessarily equal.

In the algorithm of the case study $\delta$ is taken $\delta=0.05 \mathrm{~mm}$. Other $\delta$-values can be, obviously, used depending on the case.

\subsection{Suggested position tolerances sets}

Suggested DRFs produced in step (b) of the analysis are qualified as a subset, $R_{S A G \_} D R F$, of the candidate DRFs set, $\mathrm{R}_{\mathrm{CAN} \_} \mathrm{DRF}$, in accordance with their conformance with the measured location coordinates and the application or not of the Maximum or Least Material Conditions to the RE-feature size.

(i) RE-feature size deviations are not taken into account

Qualification criterion for Suggested DRFs is formulated as, 
$\max \left(\Delta \mathrm{X}_{\mathrm{ij}}^{\mathrm{M}}, \Delta \mathrm{Y}_{\mathrm{ij}}^{\mathrm{M}}\right) \leq \mathrm{T}_{\mathrm{POS}}$

where,

$\Delta X_{\mathrm{ij}}^{\mathrm{M}}=\left(\operatorname{maxR} \_\mathrm{X}_{\mathrm{ij}}^{\mathrm{M}}-\operatorname{minR} \_\mathrm{X}_{\mathrm{ij}}^{\mathrm{M}}\right), \Delta \mathrm{Y}_{\mathrm{ij}}^{\mathrm{M}}=\left(\operatorname{maxR} \_\mathrm{Y}_{\mathrm{ij}}^{\mathrm{M}}-\operatorname{minR} \_\mathrm{Y}_{\mathrm{ij}}^{\mathrm{M}}\right)$

(ii) Maximum or Least Material Conditions applied to RE-feature size

This is the case when constraint (8) is not satisfied and $\mathrm{DRF}_{\mathrm{i}}$ 's can only be further considered when Maximum or Least Material Conditions are taken into account. From equation (2),

$\max \left(\Delta \mathrm{X}_{\mathrm{ij}}^{\mathrm{M}}, \Delta \mathrm{Y}_{\mathrm{ij}}^{\mathrm{M}}\right) \leq \max _{\mathrm{POS}}$

Sets of Suggested Theoretical RE-feature Location Dimensions, $\mathrm{R}_{\mathrm{SAG} \_} \mathrm{X}_{\mathrm{i}}, \mathrm{R}_{\mathrm{SAG} \_} \mathrm{Y}_{\mathrm{i}}$, are filtered out of the sets of the candidate dimensions, $R_{C A N} X_{i}, R_{C A N} Y_{i}$, through the implementation of the relationships,

$$
\begin{aligned}
& \left|\mathrm{X}_{\mathrm{im}}-\mathrm{X}_{\mathrm{ij}}^{\mathrm{M}}\right| \leq \frac{\operatorname{maxT}_{\mathrm{POS}}}{2}, \quad\left|\mathrm{Y}_{\mathrm{ik}}-\mathrm{Y}_{\mathrm{ij}}^{\mathrm{M}}\right| \leq \frac{\operatorname{maxT}_{\mathrm{POS}}}{2} \\
& \mathrm{~m}=1,2, \ldots, \mathrm{p} ; \quad \mathrm{k}=1,2, \ldots, \mathrm{q} ; \quad \mathrm{j}=1,2, \ldots, \mathrm{u}
\end{aligned}
$$

and the constraint imposed by the geometry of a positional tolerance,

$$
\left(X_{i m}-X_{i j}^{M}\right)^{2}+\left(Y_{i k}-Y_{i j}^{M}\right)^{2} \leq\left(\frac{T_{P O S}}{2}\right)^{2}
$$


$\mathrm{m}=1,2, \ldots, \mathrm{p} ; \quad \mathrm{k}=1,2, \ldots, \mathrm{q} ; \quad \mathrm{j}=1,2, \ldots, \mathrm{u}$

Dimensions that do not satisfy constraint (12) can only be further considered in conjunction with constraint (10) i.e. when Maximum or Least Material Conditions are used,

$\left(X_{i m}-X_{i j}^{M}\right)^{2}+\left(Y_{i k}-Y_{i j}^{M}\right)^{2} \leq\left(\frac{T_{P O S}+M_{j}-M M C D}{2}\right)^{2}$

or,

$$
\begin{aligned}
& \left(\mathrm{X}_{\mathrm{im}}-\mathrm{X}_{\mathrm{ij}}^{\mathrm{M}}\right)^{2}+\left(\mathrm{Y}_{\mathrm{ik}}-\mathrm{Y}_{\mathrm{ij}}^{\mathrm{M}}\right)^{2} \leq\left(\frac{\mathrm{T}_{\mathrm{POS}}+\mathrm{LMCD}-\mathrm{MD}_{\mathrm{j}}}{2}\right)^{2} \\
& \mathrm{~m}=1,2, \ldots, \mathrm{p} ; \quad \mathrm{k}=1,2, \ldots, \mathrm{q} ; \quad \mathrm{j}=1,2, \ldots, \mathrm{u}
\end{aligned}
$$

\subsection{Preferred position tolerances and final position tolerance assignment}

They are obtained from the output of the previous step (b) using appropriate rules and guidelines as they are datums that prevent tolerances from stacking up excessively, datum features with the lowest form and orientation errors, preferred numbers, decimals restriction etc. Preference can also be given to position tolerances that are qualified regardless of the application of the Maximum or Least Material Conditions to the REfeature size. The option suits better for floating fastener cases where alignment is of prime interest.

Final tolerance assignment is carried out by selecting the most relaxed one of the preferred tolerances and compatible with the machine shop capabilities and expertise. 


\section{Case Study and Discussion}

For a reverse engineered component of a working assembly assignment of position tolerances was carried out using the developed methodology. Interchangeability and cost competency within the machine shop capabilities and expertise were required. Two such intact parts were available for measurements, $(u=2)$. The algorithm, based on the relationships (1) - (14), was implemented in the MATLAB environment.

For the paper economy the allocation of the position tolerance for the through Hole-1, figure 4(a), is only here presented and discussed. The problem constitutes a typical floating fastener case. The dimensional tolerance $\varnothing 5 \mathrm{H} 7$ of Hole-1 and the minimum functional clearance $0.1 \mathrm{~mm}$ were known. Measured input data for the algorithm are given in table 2. They were obtained from a CMM (Mistral, Brown \& Sharpe-DEA) with ISO 10360-2 max. permissible error $3.5 \mu \mathrm{m}$. The number and distribution of sampling points conformed with the recommendations of BS7172:1989 (9 points for planes and 15 for cylinders). Suggested, preferred and final results are included in table 3 and table 4.

\section{[Insert Figure 4 about here] \\ [Insert Table 2(a) and 2(b) about here]}

Out of all the possible datums, e.g. figure 4(b), an initial set of four ones A, B, C, D was interactively recognized, figures $4(\mathrm{c})$ and $4(\mathrm{~d})$. Out of 36 possible between them combinations in couples and in triads, the set of candidate DRF's, $\mathrm{R}_{\mathrm{CAN} \_} \mathrm{DRF}$, comprising of four members (n=4) was established in step (a), $|\mathrm{A}| \mathrm{B}|\mathrm{C}|,|\mathrm{A}| \mathrm{C}|\mathrm{B}|,|\mathrm{A}| \mathrm{B}|\mathrm{D}|$, $|\mathrm{A}| \mathrm{D}|\mathrm{B}|$. For $\delta=0.05 \mathrm{~mm}$ candidate theoretical dimensions have been then obtained, equations (5)-(7), in two sets per DRF, $R_{C A N} X_{i}, R_{C A N} Y_{i}$, with $p=23,23,23,23$ and $q=23$, 
$23,24,24$ respectively. These are reduced in the following step (b) to 11 suggested position tolerances of table 3 . The quantity of the suggested results is strongly influenced by the membership of $\mathrm{R}_{\mathrm{CAN} \_\mathrm{DRF}}$, parameter $\delta$ of equations (6) and the number of available reference components. The preferred tolerances of the table 4 were obtained through the application of rules and guidelines mentioned in the previous Section. Taking into account that all three preferred tolerances are of the same easily achieved size, the position tolerance with Datum Reference Frame $|\mathrm{A}| \mathrm{D}|\mathrm{B}|$ and theoretical dimensions $\mathrm{X}=81.000 \mathrm{~mm}, \mathrm{Y}=6.100 \mathrm{~mm}$, as best suited for component location for machining, was finally assigned. This tolerance assignment was experimentally verified and well approved by fitting reconstructed components in existing and in use assemblies.

Time needed for the above work was 10min (CMM-measurements) $+6 \mathrm{~min}$ (Computer aided implementation $)=16 \mathrm{~min}$. The conventional, human-based, way for the problem solution would have taken considerably longer time and cost, without a grounded assurance for the best results, i.e. 10min (CMM-measurements) + Trial and error time ...

[Insert Table 3 and Table 4 about here]

\section{Conclusions}

Considering that tolerances in component reconstruction are crucial for component performance and interchangeability, assignment of the appropriate geometrical and dimensional accuracy data in RE is extremely difficult due to the lack of adequate information. This is particularly true for the frequently met position tolerances. The developed and presented in this paper methodology produces, in reasonable time, realistic 
results for position tolerancing in industrial reverse engineering and can be used both for rotational and prismatic features. The method can be directly integrated into a CAD environment for reverse engineering. Further development is under way in order the method to include MMC / LMC application to datums, fixed fasteners and position tolerance size not equally distributed between the mating parts.

\section{References}

Anselmetti, B. and Louati, H., Generation of manufacturing tolerancing with ISO standards, Int. J. Mach. Tools Manu., 2005, 45, 1124-1131.

ASME Y14.5.1M-1994, Mathematical Definition of Dimensioning and Tolerancing Principles, 1994 (The American Society of Mechanical Engineers: New York).

ASME Y14.5M-1994, Dimensioning and Tolerancing, 1994 (The American Society of Mechanical Engineers: New York).

Borja, V., Harding, J.A. and Bell, B., A conceptual view on data-model driven reverse engineering, Int. J. Prod. Res., 2001, 39(4), 667-687.

Cheraghi, S.H., Jiang, G. and Ahmad, J.S., An efficient approach for the identification of candidate datum set for a nominally flat primary datum feature, Int. J. Mach. Tools Manu., 2003, 43, 329-336.

Cho, N. and Tu, J.F., Quantitive circularity tolerance analysis and design for 2D precision assemblies, Int. J. Mach. Tools Manu., 2002, 42, 1391-1401.

Drake, P.J., Dimensioning and Tolerancing Handbook, pp. 22/1-22/26 \& 23/1-23/10, 1999, (McGraw - Hill: New York). 
ISO 5458:1998, Geometrical product specifications (GPS) - Geometrical tolerancing Positional tolerancing, 1998 (The International Organization for Standardization: Geneva).

Jiang, G. and Cheraghi, S. H., Evaluation of 3-D feature relating positional error, Precision Engineering, 2001, 25, 284-292.

Kaisarlis, G.J., Diplaris, S.C. and Sfantsikopoulos, M.M., A Knowledge-Based System for Tolerance Allocation in Reverse Engineering. Proceedings of $33^{\text {rd }}$ International MATADOR Conference, Manchester, 13-14 July 2000, pp. 527-532, 2000, (Springer Verlag: London).

Kaisarlis, G.J., Diplaris, S.C. and Sfantsikopoulos, M.M., Datum Identification in Reverse Engineering. Proceedings of the IFAC-MiM'04 Conference on Manufacturing, Modelling, Management and Control, Athens, 21-22 October 2004, 2006, (Elsevier: Amsterdam).

Lehtihet, E.A. and Gunasena, N.U., On the composite position tolerance for patterns of holes, Annals of the CIRP, 1991, 40, 495-498.

Motavalli, S. and Shamsaasef, R., Object-oriented modeling of a feature-based reverse engineering system, Int. J. Computer Integrated Manuf., 1996, 9(5), 354-368.

Ngoi, B.K.A., Lim, B.H. and Ong, A.S., The Nexus method for evaluating geometric dimensioning and tolerancing problems with position callout, Proc. Inst. Mech. Eng. Part B - J. Eng. Manuf., 2000, 214, 235-241.

Pandya, G., Lehtihet, E.A. and Cavalier, T.M., Tolerance design of datum systems, Int. J. Prod. Res., 2002, 40(4), $783-807$.

Park, S. and Lee, K., Mathematical modeling of geometric tolerance propagation, considering effects of datums, Proc. Inst. Mech. Eng. Part B - J. Eng. Manuf., 2001, 215, 1191-1201. 
Thompson, W.B., Owen, J.C., de St. Germain, H.J., Stark Jr, S.R. and Henderson, T., Feature-based reverse engineering of mechanical parts, IEEE Transactions on Robotics and Automation, 1999, 15(1), 57-66.

Várady, T. and Martin, R., Reverse Engineering. In Handbook of computer aided geometric design, edited by G. Farin et al., pp. 651-681, 2002, (Elsevier Science Publishers B.V.: North Holland).

Volvo Corporate Standard SDT 112-0003E, Geometrical tolerances indication and definitions, 2004 (Volvo Car Corporation). Available online at: http://www.tech.volvo.se/standard/docs/112-0003.pdf (accessed 07/05/2006).

VPERI (Virtual Parts Engineering Research Initiative) - Final Report, Workshop on Legacy Systems Engineering, Arizona State University, Tempe, 5-6 June 2003. Available online at: http://dal.asu.edu/special_events/finalReport.pdf (accessed 07/05/2006).

Werghi, N., Fisher, R., Robertson, C. and Ashbrook, A., Object reconstruction by incorporating geometric constraints in reverse engineering, Comput. Aided Des., 1999, 31, 363-399.

Werghi, N., Fisher, R., Ashbrook, A. and Robertson, C., Shape reconstruction incorporating multiple nonlinear geometric constraints, Constraints, 2002, 7, 117-149.

Xi, M., Lehtihet, E.A. and Cavalier, T.M., Numerical approximation approach to the producibility of composite position tolerance specifications for pattern of holes, Int. J. Prod. Res., 2004, 42(2), 243-266. 


\section{Tables}

Table 1. Issues of Position Tolerance Assignment in RE.

i. The number of available RE components that will be measured. The more RE parts are measured, the more reliable will be the extracted results. Typically, the number of available RE components is extremely limited, usually ranging from less than ten to a single one article.

ii. Off the shelf, worn or damaged RE components. Off the shelf RE components are obviously ideal for the job, given that the extent of wear or damage is for the majority of cases difficult to be quantified or compensated.

iii. Accessibility of the mating part (-s). Mating parts are frequently inaccessible or physically impossible to be measured.

iv. Floating or fixed fastener type of assembly.

v. The size and the form (circular or square) of the position tolerance zone.

vi. Candidate datums and datum reference frames. Depending on the case more possible DRFs may be considered.

vii. Precedence of datum features in DRFs.

viii. Theoretical (basic) dimensions involved.

ix. Assignment of Maximum Material and Least Material Conditions to both the RE-feature and RE datum features.

x. Measurement instrumentation capabilities. Measurements methods and software. 
Table 2(a). Case study Datum related measured input data.

\begin{tabular}{|c|c|c|c|c|c|c|}
\hline \multirow{2}{*}{$\begin{array}{l}\text { Datum } \\
\text { Feature }\end{array}$} & \multicolumn{2}{|c|}{$\mathrm{MFE}_{\mathrm{DF}}(\mathbf{m m})$} & \multicolumn{2}{|c|}{$\operatorname{MOE}_{\mathrm{F}}(\mathrm{mm})$} & \multicolumn{2}{|c|}{$\operatorname{MOE}_{\mathrm{DF}}(\mathrm{mm})$} \\
\hline & Part1 & Part2 & Part1 & Part2 & Part1 & Part2 \\
\hline \multirow[t]{2}{*}{$A$} & 0.008 & 0.014 & 0.006 & 0.004 & - & - \\
\hline & & & & & A-0.034 & A-0.021 \\
\hline \multirow[t]{2}{*}{$\boldsymbol{B}$} & 0.019 & 0.012 & 0.013 & 0.011 & $\mathrm{C}-0.057$ & C-0.048 \\
\hline & & & & & D-0.066 & D-0.052 \\
\hline \multirow{3}{*}{$C$} & & & & & A- 0.042 & A- 0.038 \\
\hline & 0.026 & 0.018 & 0.011 & 0.016 & & \\
\hline & & & & & B-0.075 & B-0.061 \\
\hline \multirow{3}{*}{$D$} & & & & & A-0.046 & $\mathrm{A}-0.051$ \\
\hline & 0.031 & 0.035 & 0.022 & 0.024 & & \\
\hline & & & & & B-0.080 & B-0.069 \\
\hline
\end{tabular}

Table 2(b). Case study Feature related measured input data.

\begin{tabular}{ccccccc}
\hline & MD (mm) & & $|\mathbf{A}| \mathbf{B}|\mathbf{C}|$ & $|\mathbf{A}| \mathbf{C}|\mathbf{B}|$ & $|\mathbf{A}| \mathbf{B}|\mathbf{D}|$ & $|\mathbf{A}| \mathbf{D}|\mathbf{B}|$ \\
\hline \multirow{2}{*}{$\boldsymbol{P a r t 1}$} & 5.005 & $\mathrm{X}_{\mathrm{i} 1}^{\mathrm{M}}$ & 81.002 & 80.977 & 81.004 & 80.985 \\
& & $\mathrm{Y}_{\mathrm{i} 1}^{\mathrm{M}}$ & 6.015 & 6.040 & 6.072 & 6.096 \\
\hline \multirow{2}{*}{$\boldsymbol{P a r t 2}$} & 5.008 & $\mathrm{X}_{\mathrm{i} 2}^{\mathrm{M}}$ & 81.041 & 81.019 & 81.042 & 81.034 \\
& & & & & & \\
& & $\mathrm{Y}_{\mathrm{i} 2}^{\mathrm{M}}$ & 5.978 & 6.003 & 6.061 & 6.085 \\
\hline
\end{tabular}


Table 3. Case study results: suggested position tolerances.

\begin{tabular}{|c|c|c|c|c|}
\hline $\mathbf{T}_{\mathbf{P O S}}$ & DRF & $\mathbf{X}$ & $\mathbf{Y}$ & $\begin{array}{l}\text { Material } \\
\text { Modifier }\end{array}$ \\
\hline$\varnothing 0.100$ & $|\mathrm{~A}| \mathrm{B}|\mathrm{C}|$ & 81.000 & 6.000 & - \\
\hline$\varnothing 0.100$ & $|\mathrm{~A}| \mathrm{B}|\mathrm{C}|$ & 81.050 & 6.000 & MMC \\
\hline$\varnothing 0.100$ & $\mathrm{~A}|\mathrm{~B}| \mathrm{C} \mid$ & 81.050 & 6.000 & LMC \\
\hline$\varnothing 0.100$ & $\mathrm{~A}|\mathrm{C}| \mathrm{B} \mid$ & 81.000 & 6.000 & - \\
\hline$\varnothing 0.100$ & $\mathrm{~A}|\mathrm{C}| \mathrm{B} \mid$ & 81.000 & 6.050 & MMC \\
\hline$\varnothing 0.100$ & $|\mathrm{~A}| \mathrm{C}|\mathrm{B}|$ & 81.000 & 6.050 & LMC \\
\hline$\varnothing 0.100$ & $|\mathrm{~A}| \mathrm{B}|\mathrm{D}|$ & 81.000 & 6.050 & - \\
\hline$\varnothing 0.100$ & $|\mathrm{~A}| \mathrm{B}|\mathrm{D}|$ & 81.050 & 6.050 & MMC \\
\hline$\varnothing 0.100$ & $|\mathrm{~A}| \mathrm{B}|\mathrm{D}|$ & 81.050 & 6.050 & LMC \\
\hline$\varnothing 0.100$ & $|\mathrm{~A}| \mathrm{D}|\mathrm{B}|$ & 81.000 & 6.100 & - \\
\hline$\varnothing 0.100$ & $|\mathrm{~A}| \mathrm{D}|\mathrm{B}|$ & 81.000 & 6.050 & - \\
\hline
\end{tabular}


Table 4. Case study results: preferred and final RE position tolerances.

\begin{tabular}{|c|c|c|c|c|}
\hline $\mathbf{T}_{\mathbf{P O S}}$ & DRF & $\mathbf{X}$ & $\mathbf{Y}$ & $\begin{array}{l}\text { Material } \\
\text { Modifier }\end{array}$ \\
\hline$\varnothing 0.100$ & $\mathrm{~A}|\mathrm{~B}| \mathrm{C} \mid$ & 81.000 & 6.000 & - \\
\hline$\varnothing 0.100$ & $|\mathrm{~A}| \mathrm{C}|\mathrm{B}|$ & 81.000 & 6.000 & - \\
\hline$\varnothing 0.100$ & $|\mathrm{~A}| \mathrm{D}|\mathrm{B}|$ & 81.000 & 6.100 & - \\
\hline \multicolumn{5}{|c|}{ RE Position Tolerances } \\
\hline$\varnothing 0.100$ & $|\mathrm{~A}| \mathrm{D}|\mathrm{B}|$ & 81.000 & 6.100 & - \\
\hline
\end{tabular}




\section{List of figure captions}

Figure 1. Position tolerancing of a cylindrical feature (Adapted from Volvo Corporate Standard 2004)

Figure 2. Influence of datum precedence in a DRF to the location of a feature

Figure 3. Conceptual overview of the method

Figure 4. Application example component 


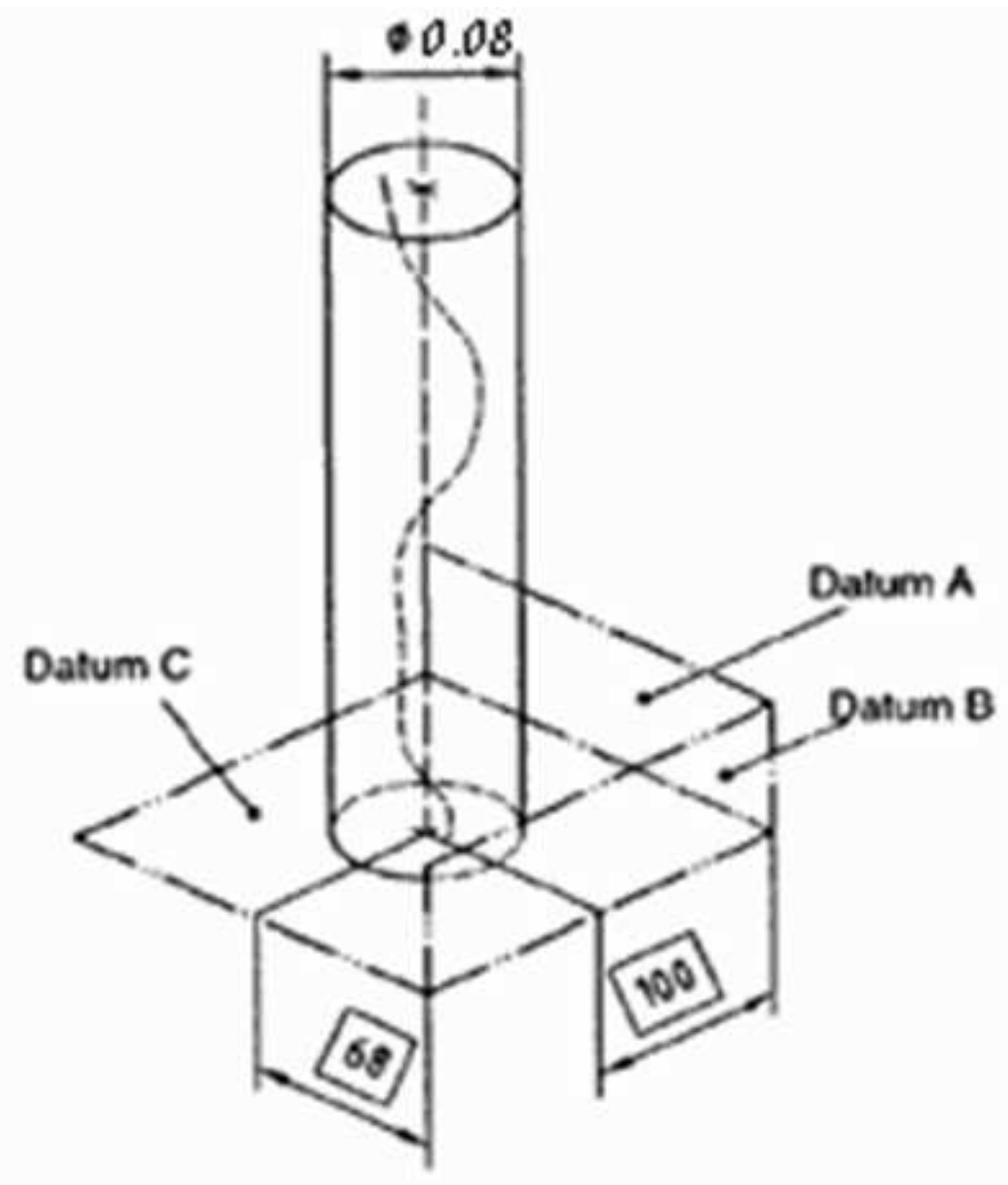

Position tolerancing of a cylindrical feature (Adapted from Volvo Corporate Standard 2004 ) $17 \times 19 \mathrm{~mm}(600 \times 600 \mathrm{DPI})$ 


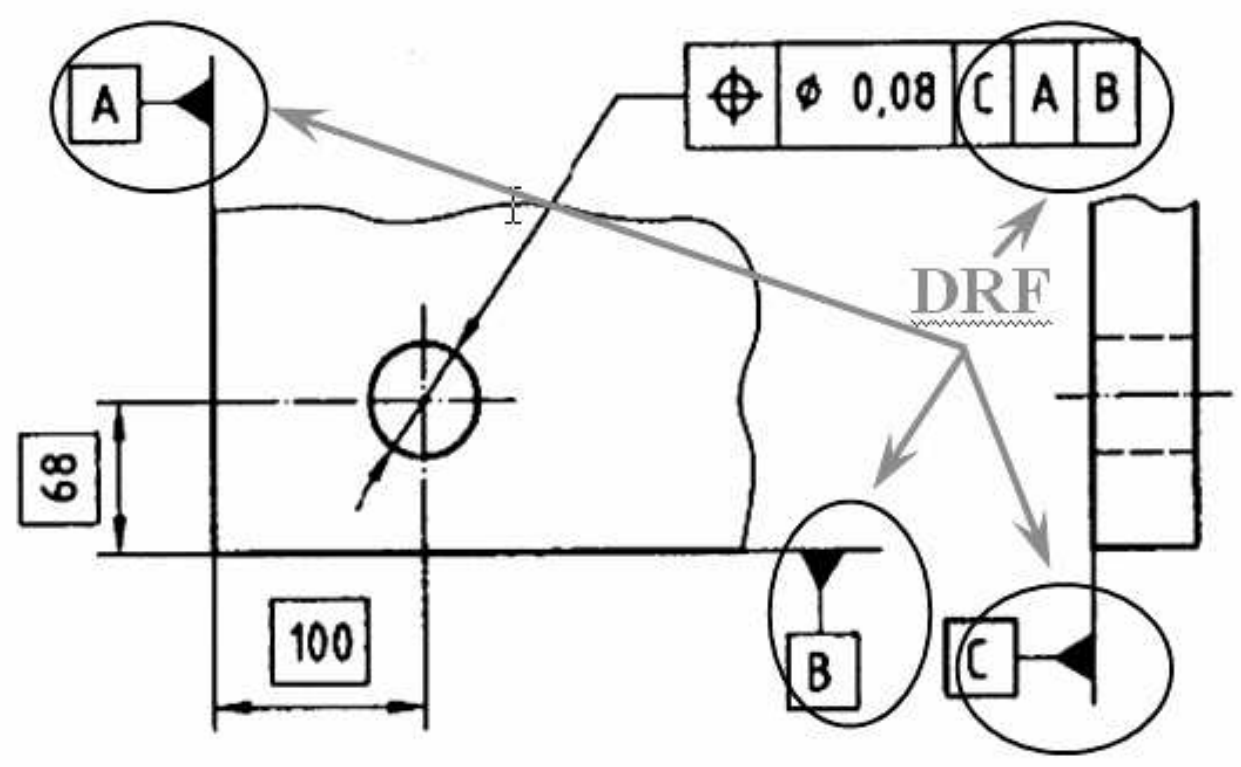

Position tolerancing of a cylindrical feature (Adapted from Volvo Corporate Standard 2004 ) $28 \times 17 \mathrm{~mm}(500 \times 500 \mathrm{DPI})$ 

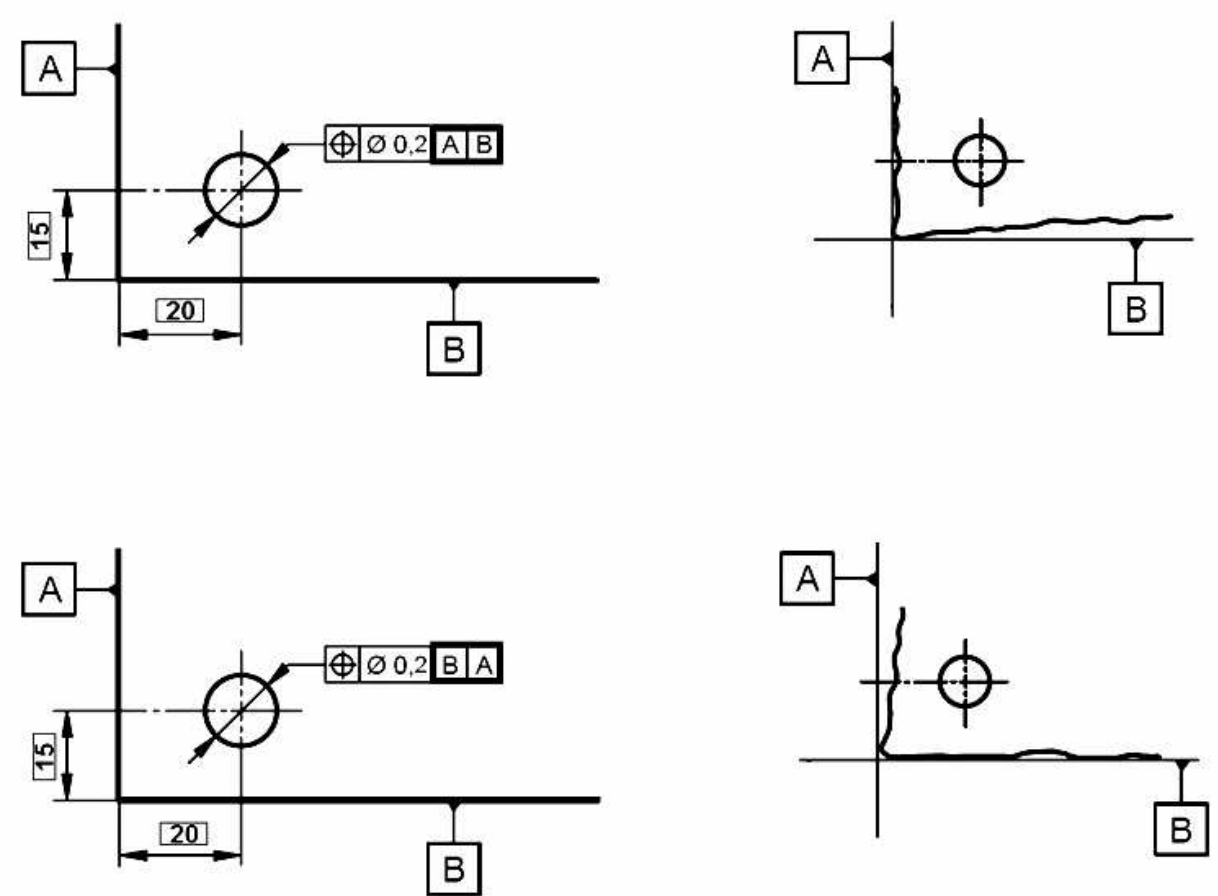

Influence of datum precedence in a DRF to the location of a feature $211 \times 149 \mathrm{~mm}(96 \times 96 \mathrm{DPI})$ 


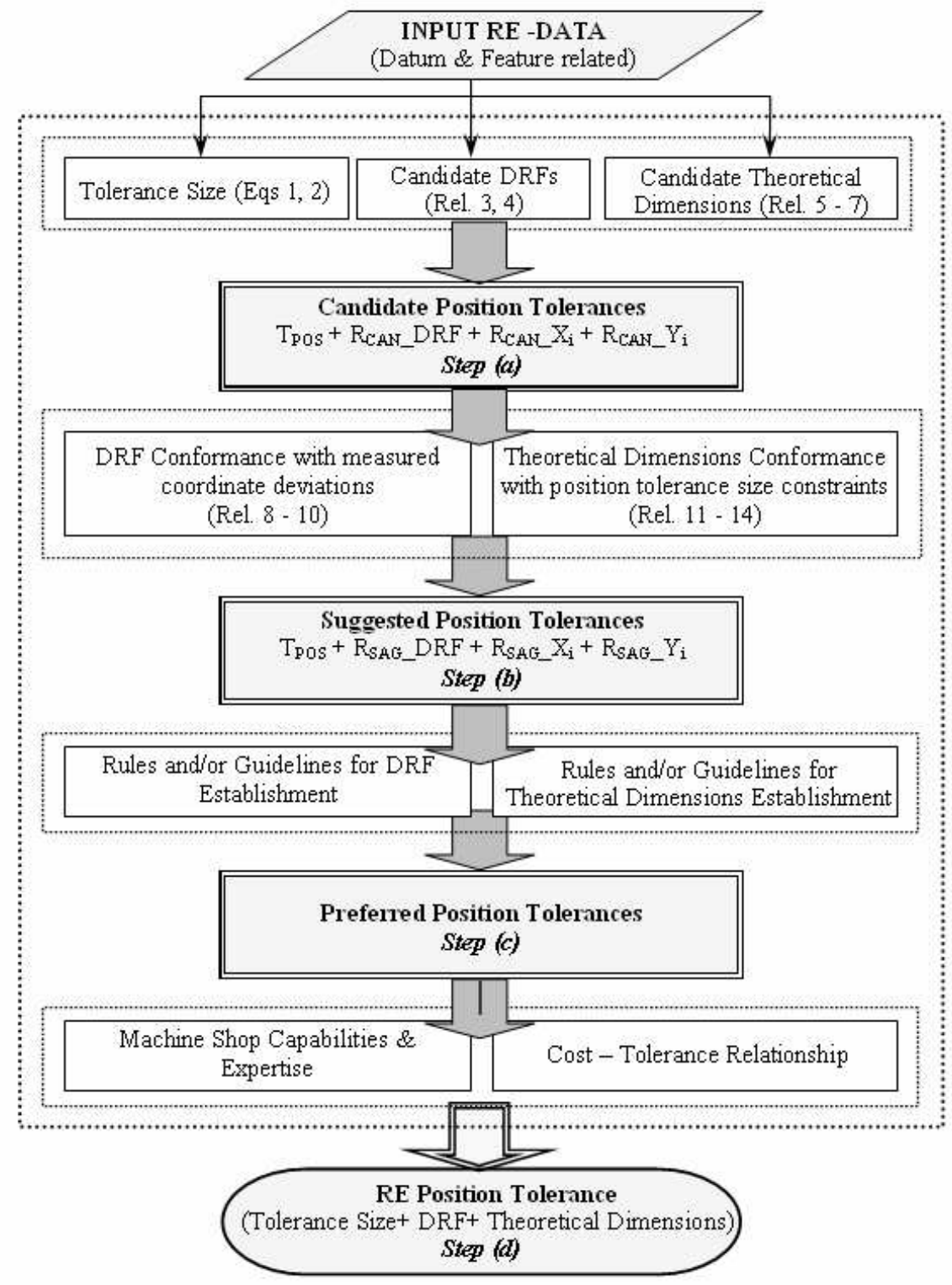

Conceptual overview of the method $29 \times 39 \mathrm{~mm}(500 \times 500$ DPI $)$ 


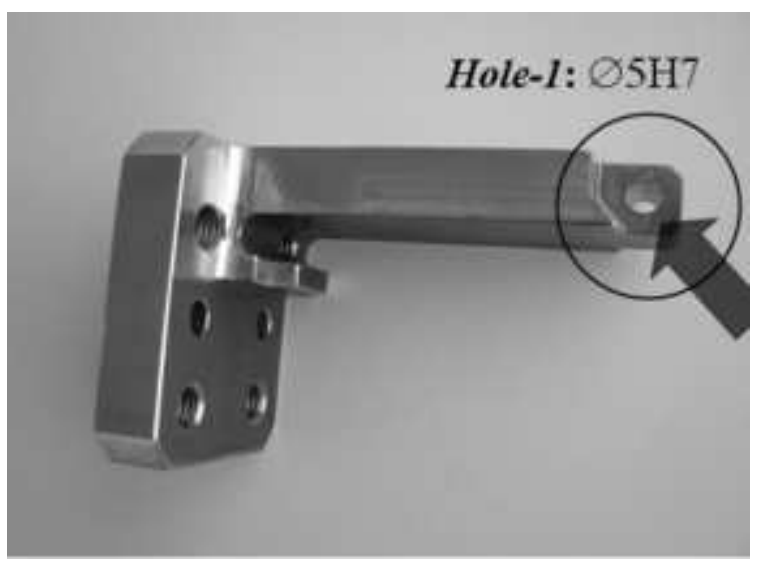

Application example component $12 \times 8 \mathrm{~mm}(600 \times 600 \mathrm{DPI})$ 


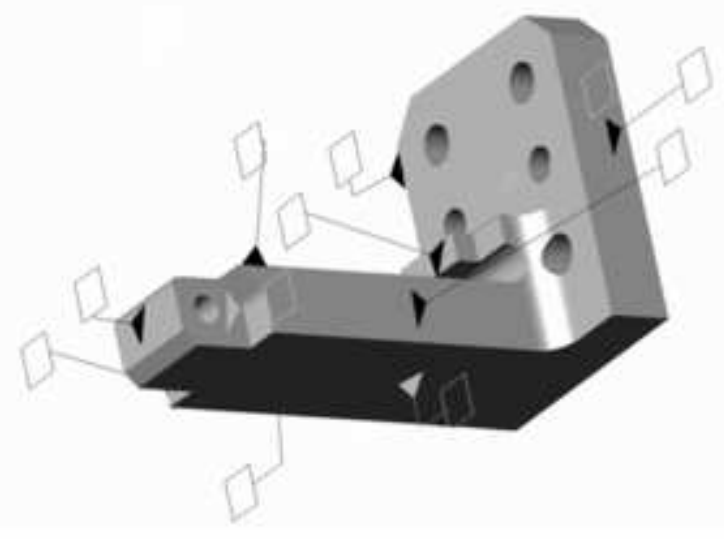

Application example component $12 \times 9 \mathrm{~mm}(600 \times 600 \mathrm{DPI})$ 


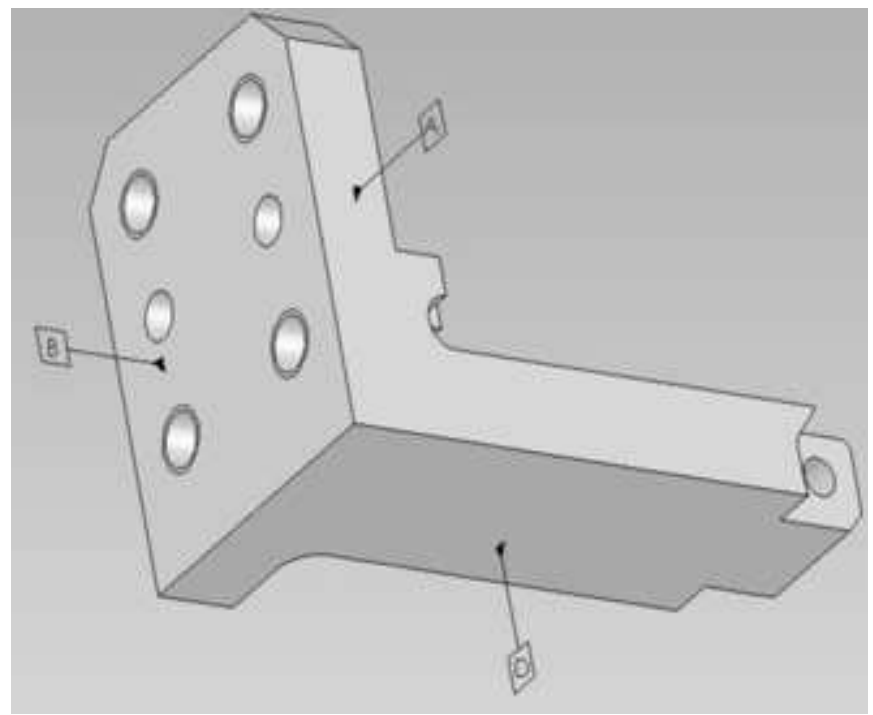

Application example component $13 \times 11 \mathrm{~mm}(600 \times 600 \mathrm{DPI})$ 


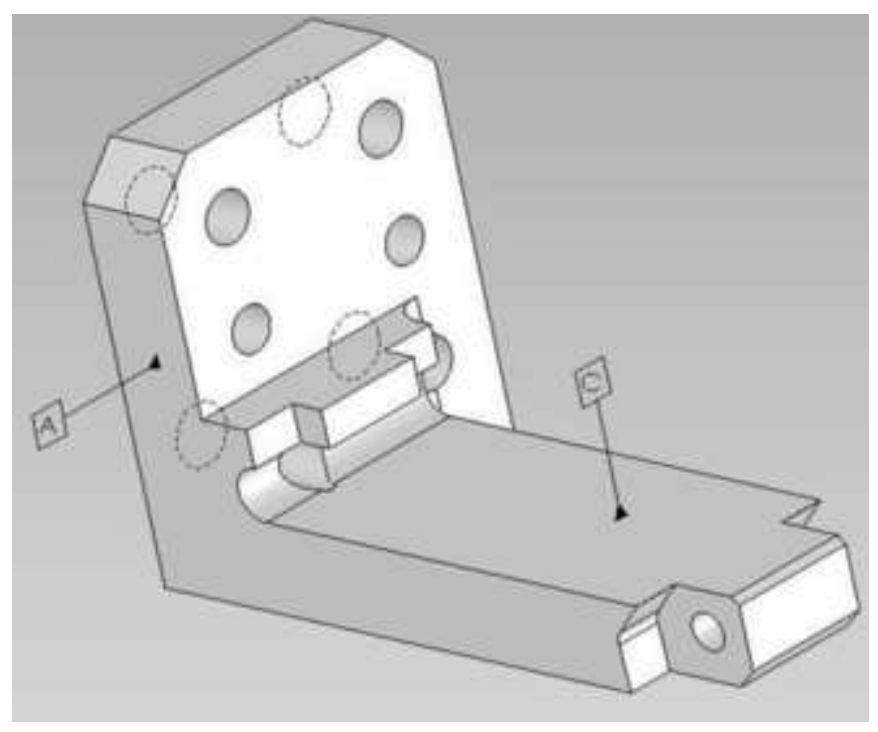

Application example component $13 \times 11 \mathrm{~mm}(600 \times 600 \mathrm{DPI})$ 